\title{
Emotional Intelligence as a Protective Factor in Times of Educational Reforms: First Steps of an Investigation on Italian High-School Teachers
}

\author{
Luisa Broli, Carlo Berrone, \\ Roberta Renati, Maria Assunta Zanetti \\ Department of Psychology, \\ University of Pavia, Italy \\ luisa.broli, carlo.berrone, roberta.renati, \\ zanetti\{@unipv.it\}
}

\begin{abstract}
As several international researches have shown, the affective domain plays a crucial role in teaching, especially in times of educational reforms that represent a potential stressor. The purpose of this article is to present the preliminary phases of a work in progress consisting of a series of studies about some psychological aspects of the teaching profession coping with change. Inspired by $a$ recent, substantial reform of the Italian high-school system, our research project is aimed at expanding the body of findings on teacher emotional intelligence, an emerging topic in educational psychology, as it is demonstrated by a flourishing literature. The relationships between emotional intelligence, self-efficacy beliefs, job satisfaction and burnout are the other areas included in our investigation. A sample of about 350 Italian highschool teachers was asked to complete anonymously a battery of self-report questionnaires. Data analyses are currently being performed. Our work intends to be a significant contribution to the debate about emotional intelligence as a plausible protective factor against teachers' vulnerability heightened by an increased performativity demand.
\end{abstract}

\section{Introduction}

Emotions are of fundamental importance in educational settings: they are linked to teachers' well-being and sense of identity and influence both teachers' and students' cognition, motivation and behaviors.

\author{
Letizia Palazzeschi, Annamaria Di Fabio \\ Department of Psychology, \\ University of Florence, Italy \\ letizia.palazzeschi@gmail.com, \\ adifabio@psico.unifi.i
}

The complexity of research on emotions in teaching is demonstrated by the plurality of quantitative and qualitative methodological approaches adopted to investigate the topic. Since Hargreaves stated that emotions are the heart of teaching [1], international literature has shown an increasing interest about instructional practices as an array of both cognitive and emotional dynamics and challenges that may influence teachers' psychosocial functioning in different scenarios and require suitable management in order to sustain a state of general well-being.

Therefore, emotional skills are particularly crucial when teachers have to face educational reforms that imply a reconsideration of their professional competencies. For example, the affective domain is one of the components of a socio-constructivist model highlighting the competencies required for accompanying changes in organizations, schools included: this model postulates that human beings' awareness of their emotional reactions (e.g. enthusiasm, pleasure, withdrawal, frustration, resistance) influences their attitudes and their openness to innovations [2].

Several researches about the impact of emotions on teachers' lives have shown that emotions are important to pedagogical practices, to studentteacher relationships, to issues of reform efforts and processes of change [3]. Teachers respond emotionally to demographic, social and cultural changes and to large-scale educational restructurings in a variety of ways: some prove to be willing to support innovations, while others experience distress, tend to feel vulnerable and consequently display resistance to transformation.

The idea of vulnerability as a fundamental characteristic of teaching is the background of a 
study that analyzed the interplay of vulnerability, the confrontation with changing working conditions and teachers' (emotional) coping with them [4].

A quantitative perspective about teacher emotion research is represented by the studies concerning teacher emotional intelligence (EI).

Generally definable as an interaction between emotion and cognition leading to adaptive functioning, EI has been conceptualized either as a set of improvable and interrelated abilities or as an individual trait similar to personality characteristics; for example, according to Mayer and Salovey's four-branch model, EI involves the ability to perceive accurately, appraise, and express emotion; the ability to access and/or generate feelings when they facilitate thought; the ability to understand emotion and emotional knowledge; and the ability to regulate emotions to promote emotional and intellectual growth [5].

EI has been investigated with regard to its relationships with various life outcomes. The association between EI and health was the focus of two recent meta-analyses including correlational studies based upon the above mentioned conceptualizations: the first [6] systematically reviewed 44 studies (encompassing 7,898 participants) and highlighted significant positive relationships between EI and mental, psychosomatic and physical health (the association with mental health was stronger when EI was measured as a trait); the second [7], conducted on a total of 19,815 subjects participating in 105 studies, confirmed the value of EI as a plausible health predictor. An overview on emotionally intelligent individuals' functioning can be found in Brackett et al. [8], who explored the intra - and interpersonal implications of EI for global well-being in everyday life and for success in managing conflict and stress in both academic and workplace settings.

The assessment of teachers and students' EI is an emerging issue in educational psychology. Several recent quantitative studies focused on the relationship between teacher EI, self-efficacy, job satisfaction and burnout. A positive relationship between EI and job satisfaction was demonstrated in a sample of Greek special education teachers [9]; similarly, a significant impact of teachers' EI on their job satisfaction was found in a Hong Kong sample [10]. Furthermore, some studies showed a positive relationship between teachers' EI and selfefficacy beliefs in different countries [11, 12, 13].

Teachers' self-efficacy is a multidimensional construct that may be conceptualized as teachers' beliefs about their capability to influence student learning through the planning, the organization and the implementation of activities that lead to the attainment of educational goals [14].

Job satisfaction, in general, can be defined as a positive affect toward one's profession, associated with pleasant emotional states experienced in the exercise of it; in teaching, as in many other professional domains, job satisfaction may refer both to the opportunities for long-term career development, and to the appraisal of specific daily aspects (organizational and relational ones included).

A conceptual model in which teachers' individual and collective efficacy beliefs operate as determinants of their job satisfaction was illustrated by an Italian study and corroborated by multilevel structural equation modeling analyses [15]. Another Italian research - on a sample of primary, middle and high school teachers - showed that job satisfaction depends on positive affect and on selfefficacy beliefs [16]. According to a recent study on Norwegian elementary and middle school teachers, self-efficacy is directly related to job satisfaction and negatively related to teacher burnout [17]. Moreover, some studies revealed an increasing interest about the relationship between teachers' EI and burnout [18].

Burnout, described by Maslach and Jackson as a three-dimensional syndrome consisting of emotional exhaustion, depersonalization and reduced personal accomplishment [19], has been studied in a variety of helping professions, teachers included, characterized by intense and caring interactions.

A recent research indicated that Greek special education teachers with high-perceived EI are likely to experience less burnout and greater job satisfaction [20]. Another study investigated the association between emotion regulation ability, assessed by the Mayer - Salovey - Caruso Emotional Intelligence Test (MSCEIT) - and burnout in a sample of British secondary school teachers: the results demonstrated that emotionregulation ability is positively associated with personal accomplishment [21].

\section{Aims and hypotheses}

To address the above issues we are working on a series of studies aimed at: 1) expanding the body of findings on teachers' perceived EI, 2) investigating teachers' self-efficacy beliefs, job satisfaction and burnout, 3) exploring the correlations between EI, self-efficacy, job satisfaction and burnout, 4) implementing intervention research programs meant to raise awareness and self-reflexivity about emotional 
intelligence and its effects on teachers' psychosocial functioning and professional skills (with particular reference to the promotion of a positive class climate).

Our studies, indeed, are part of a research program on some aspects of the teaching profession in a period of frequent reforms in the Italian school system. There are good reasons to presume that EI is a significant protective factor when an increased performativity demand makes teachers more vulnerable to stress factors and burnout. Personal resources in coping with changes may increase feelings of personal accomplishment and have a positive influence on teachers' global well-being.

The hypotheses we formulated for our study are the following: (a) Emotional intelligence is positively related to self-efficacy, (b) Emotional intelligence is positively related to job satisfaction, (c) Emotional intelligence is negatively related to burnout, (d) Self-efficacy is positively related to job satisfaction.

\section{Method}

\subsection{Participants and procedure}

We chose to conduct our investigation on highschool teachers because they are currently coping with a demanding curriculum reform that started in September 2010, without neither previous widespread experimentation nor accompaniment actions.

Teachers from 15 high schools located in two regions of northern Italy (Lombardy and Piedmont) were recruited to participate in the study. They were contacted by the researchers during one of the periodical meetings of the teaching staff and asked to complete anonymously a battery of self-report questionnaires measuring emotional intelligence, self-efficacy, job satisfaction and burnout; participants were also asked to provide some basic demographic information (age, gender, years of teaching, subject taught).

Teachers who completed our battery have been invited to join a training aimed not only at developing an adequate awareness about the investigated constructs and their role in teaching, but especially at promoting teachers' selfreflexivity applied to the emotional domain.

Our final sample includes about 350 subjects.

\subsection{Research instruments}

A) Self-efficacy: the Teachers' self-efficacy scale [22]. This instrument, made up of 49 items, explores five dimensions: 1) Self-efficacy in teaching practices, 2) Self-efficacy in creating a good class climate, 3) Self-efficacy in the relationships with the students and their families, 4) Self-efficacy in the relationships with extra-school contexts.

B) Emotional intelligence:

a) The Italian version of the Emotional Intelligence Scale (EIS) [23]. This 22-item tool assesses three dimensions: 1) Appraisal and expression of emotions, 2) Regulation of emotions, 3) Utilization of emotions in solving problems.

b) The Italian version of the Bar-On Emotional Quotient Inventory: Short (Bar-On EQ-I: S) [24]. This measure, including 51 items, explores four dimensions: 1) Intrapersonal, 2) Interpersonal, 3) Stress management, 4) Adaptability.

C) Job satisfaction: the Organizational Satisfaction Questionnaire [25] in an adapted 41item version developed for teachers. The instrument measures seven dimensions: 1) Task and development, 2) Organization and communication, 3) Climate, 4) Contract, 5) Image, 6) Context, 7) Workload.

D) Burnout: a 16-item scale derived from the Checkup Organizational System questionnaire [26].

\section{Discussion}

Our work-in-progress intends to be a significant contribution to the debate about the role of the affective components in the teaching profession. Indeed, we would like to expand the body of findings about EI in the school context, with particular reference to teachers' EI as a crucial factor supporting well-being in the workplace.

Both the administration of our battery and the subsequent training - with the debriefing about the investigated constructs and the presentation of the purposes and characteristics of the measures we used - can be considered a way of promoting participants' self-reflexivity applied to the affective domain; teachers' skills in reflecting upon their own emotions represent an emerging issue in educational psychology, with reference to selfknowledge, creativity and self-care practices that encourage, among others, to face challenging school contexts.

Some limitations to this research are worth noting. First, our data were derived only from selfreports (we have not investigated students' perception of teachers' emotional competencies), even if the respondents' anonymity should have lowered the risk of socially desirable answers; second, ours is a convenience sample, not a randomized one (our battery was administered only 
in the schools whose principals and teaching staffs agreed to participate), hence the generalizability of our findings will have to be confirmed by further research; furthermore, some latent variables (e.g. hypothetical factors linked to the school reform) might influence the results.

\section{Conclusion}

If our hypotheses were verified, we might conclude that EI could be considered both a protective factor against teachers' vulnerability in times of change implying an increased performativity demand, and a plausible predictor of well-being. Consequently, our findings could be useful to promote the implementation of programs aimed at supporting teachers in reflecting on and in analyzing their emotional dimensions in the educational context. The empowerment of teachers' emotional intelligence could foster their psychosocial functioning and improve class and school climate, together with students' achievement. Such programs could also help teachers to cope with the additional distress caused by substantial changes (imposed by school-system reforms) in everyday instructional practices.

\section{References}

[1] A. Hargreaves, "The emotional practice of teaching”, Teaching and Teacher Education, 1998, 14, 8, p. 835.

[2] L. Lafortune, C. Lepage, F. Persechno, and A. Altken, Professional Competencies for accompanying change, Presses de l’Université du Québec, Québec, 2009.

[3] M. Zembylas and P. A. Schutz, "Research on teachers' emotions in education: findings, practical implications and future agenda”, In P. A. Schutz and M. Zembylas (Eds.), Advances in Teacher Emotion Research, Springer, London-New York, 2009, p. 367.

[4] G. Kelchtermans, K. Ballet, and L. Piot, "Surviving diversity in times of performativity: understanding teachers' emotional experience of change”, In P. A. Schutz and M. Zembylas (Eds.), Advances in Teacher Emotion Research, Springer, London-New York, 2009, p. 218.

[5] J. D. Mayer and P. Salovey, "What is emotional Intelligence?” In P. Salovey and D. Sluyter (Eds.), Emotional development and emotional intelligence, Basic Books, New York, 1997, p. 10.

[6] N. S. Schutte, J. M. Malouff, E. B. Thorsteinsson, N. Bhullar, and S. E. Rooke, "A meta-analytic investigation of the relationship between emotional intelligence and health”, Personality and Individual Differences, 2007, 42, pp. 921-933.

[7] A. Martins, N. Ramalho, and E. Morin, “A comprehensive meta-analysis of the relationship between Emotional Intelligence and health", Personality and Individual Differences, 2010, 49, pp. 554-564.

[8] M.A.Brackett, S.E. Rivers, and P. Salovey, "Emotional Intelligence: Implications for Personal, Social, Academic, and Workplace Success", Social and Personality Psychology Compass, 2011, 5/1, pp. 88-103.

[9] M. Platsidou, “Trait emotional intelligence of Greek special education teachers in relation to burnout and job satisfaction”, School Psychology International, 2010, 31, 1, pp. 60-67.

[10] C.Wong, P.Wong and K. Z. Peng, "Effect of middle-level leader and teacher emotional intelligence on school teachers' job satisfaction: the case of Hong Kong”, Educational Management Administration Leadership, 2010, 38, 1, pp. 59-70.

[11] D. W. Chan, "Perceived emotional intelligence and self-efficacy among Chinese secondary school teachers in Hong Kong”, Personality and Individual Differences, 2004, 36, pp. 1381-1795.

[12] A. Di Fabio and L. Palazzeschi, "Emotional intelligence and self-efficacy in a sample of Italian high school teachers", Social Behavior and Personality, 2008, 36, 3, pp. 315-325.

[13] M. Rastegar and S. Memarpour, "The relationship between emotional intelligence and self-efficacy among Iranian EFL teachers”, System, 2009, 37, pp. 700-707.

[14] R. M. Klassen and M. M. Chiu, "Effects on teachers' self-efficacy and job satisfaction: teacher gender, years of experience, and job stress", Journal of Educational Psychology, 2010, 102, 3, pp. 741-756.

[15] G. V. Caprara, C. Barbaranelli, L. Borgognoni, and P. Steca, "Efficacy beliefs as determinants of teachers' job satisfaction", Journal of Educational Psychology, 2003, 95, 4, pp. 821-832.

[16] A. Moé, F. Pazzaglia, and L. Ronconi, "When being able is not enough. The combined value of positive affect and self-efficacy for job satisfaction in teaching", Teaching and Teacher Education, 2010, 26, pp. 11451153.

[17] E. M. Skaalvick and S. Skaalvik, "Teacher selfefficacy and teacher burnout: a study of relations, Teaching and Teacher Education, 2010, 26, pp. 10591069.

[18] C. Maslach and S.E. Jackson, (1986). Maslach Burnout Inventory manual (2nd ed.), Consulting Psychologists Press, Palo Alto, CA, 1986. 
[19] D. W. Chan, "Emotional intelligence and components of burnout among Chinese secondary school teachers in Honk Kong”, Teaching and Teacher Education, 2006, 22, 1042-1054.

[20] M. Platsidou, “Trait emotional intelligence of Greek special education teachers in relation to burnout and job satisfaction”, School Psychology International, 2010, 31, 1, pp. 60-67.

[21] M. Brackett, R. Palomera, J. Mojsa-Kaja, M.R. Reynes, and P. Salovey, "Emotion-regulation ability, burnout, and job satisfaction among British secondaryschool teachers", Psychology in the Schools, 2010, 47, 4, pp. 406-417.

[22] R. C. Belvedere, C. Barbaranelli, G.V. Caprara, and P. Steca, "Autoefficacia dei docenti: costruzione e contributo alla valutazione di uno strumento di misurazione”, Psicologia dell'educazione, 2010, 4, 2, pp. 237-253.

[23] N.S. Schutte, J.M. Malouff, L.E. Hall, D.J. Haggerty, J.T. Cooper, C.J. Golden, and C.J. Dornheim, "Development and validation of a measure of emotional intelligence”, Personality and Individual Differences, 1998, 25, pp. 167-177. Italian version: A. Di Fabio, M. Giannini, and L. Palazzeschi, "Intelligenza emotiva: proprietà psicometriche della versione italiana della Emotional Intelligence Scale (EIS)”, Counseling, 2008, 1, pp. 61-71.

[24] R. Bar-On, Emotional Quotient Inventory: Short, Multi-Health System, Toronto, 2002. Italian version: A. Di Fabio and L. Palazzeschi, "Bar-On Emotional Quotient Inventory: Short (Bar-On EQ-i:S): primi risultati nel contesto italiano", Counseling, in press.

[25] C. G. Cortese, "La soddisfazione per il lavoro", Sviluppo \& Organizzazione, 2004, 206, pp. 89-104.

[26] C. Maslach and M.P. Leiter, Organizational Checkup Survey, Jossey-Bass, San Francisco, 2000. Italian version: L. Borgogni, D. Galati, L. Petita, and Centro Formazione Schweitzer, Il questionario di checkup organizzativo. Manuale dell'adattamento italiano (Organizational Checkup Survey, Manual of the Italian Adaptation), O.S. Organizzazioni Speciali, Firenze, 2005. 